\title{
Vertigo after epidural morphine
}

Jane Goundrey MD FRCPC

Severe complications from the use of epidural morphine for analgesia after Caesarean section are rare. A case is reported of extreme prostrating vertigo several hours after epidural morphine injection, where the time of onset of the symptom coincided with the expected time of arrival of the morphine within intra-cerebral cerebro-spinal fluid.

Les complications sévères après injection de morphine épidurale pour l'analgésie après césarienne sont rares. Un cas est rapporté où un vertige sévère est apparu plusieurs heures après. injection de morphine épidurale où le temps d'installation du symptôme a coïncidé avec le temps prévu de l'arrivée de la morphine dans le liquide céphalo-rachidien.

While complications from the rostral spread of narcotics within the central nervous system are well known, particularly respiratory depression,' the incidence of important complications is very low in parturients. ${ }^{2}$ Problems encountered in these patients are generally only nuisance side-effects, such as pruritus, and nausea and vomiting. A recent review of epidural morphine for postoperative pain after Caesarean section found a ten per cent incidence of "dizziness"* which had not been previously recognized as an adverse effect. Profound and incapacitating vertigo associated with epidural morphine has not yet been reported in the literature.

*Fuller JG, McMorland GH, Douglas J, Palmer L, Constantine $L V$. Epidural morphine for postoperative pain after Caesarean section: a revicw. Abstract from the Proceedings of the 20th Annual Mecting of the Society of Obstetric Anesthetists and Perinatologists, San Francisco, April 27-30th 1988, p. 94.

\section{Key words}

ANAESTHESIA: obstetric;

ANALGESIA: epidural, opioids;

COMPLICATIONS: dizziness, vertigo.

From the Department of Anacsthesia, Chilliwack General Hospital, Chilliwack, British Columbia.

Address correspondence to: Dr. S.J. Goundrey, Department of Anacsthesia, Peace Arch District Hospital, 15521 Russell

Ave., White Rock, British Columbia, V4B 2 R4.
A case is reported of a parturient experiencing severe vertigo after receiving epidural morphine during an elective Caesarean section. Profound nausea, vomiting and vertigo led to a diagnosis of acute vestibular disturbance, which may or may not have been causally related to the spread of morphine within the central nervous system.

\section{Case report}

A 31-yr-old Caucasian woman presented at term for repeat elective Caesarean section. Her first child had been delivered by Caesarean section because of cephalopelvic disproportion. This had been performed under epidural anaesthesia and epidural morphine had been administered without incident. There had been no problems with the present pregnancy and the mother was a healthy nonsmoker with no previous history of vertigo.

On the morning of surgery epidural anaesthesia was instituted using two per cent $\mathrm{CO}_{2}$ lidocaine with 1:200,000 epinephrine via a catheter inserted through an \# $17 \mathrm{~g}$ Hustead needle at the $\mathrm{L}_{3-4}$ interspace. After a test dose of $3 \mathrm{ml}$, further lidocaine was administered, in increments, to a total of $18 \mathrm{ml}$. Lack of any symptoms of intravascular injection, and the amount of lidocaine and time required to achieve a block to $T_{4}$, were considered good indicators of correct epidural catheter placement.

Epidural fentanyl, $100 \mu \mathrm{g}$, was also given initially. Atropine and ephedrine were required to maintain heart rate and blood pressure respectively during the onset of the sympathetic block, despite a two litre intravenous bolus of Ringers lactate and left uterine displacement. The period of hypotension (blood pressure $65 / 30$, heart rate 40) was less than four minutes and the patient was alert and talking throughout.

The rest of the procedure was uneventful. A bolus of five units of oxytocin had been given intravenously after delivery of the baby and 20 units added per litre of Ringer's lactate for the next litre and a half of fluid given. Blood loss was estimated to be no more than $500-750 \mathrm{ml}$. After the initial period of hypotension which was associated with sympathetic blockade the patient's vital signs remained normal for the remainder of the case. Epidural morphine, $4 \mathrm{mg}$, was given over a five-minute period shortly after delivery and approximately $45 \mathrm{~min}$ after the initial dose of lidocaine. No further medication was given.

Vital signs remained normal in the recovery period and 
the nurse's notes reported that the patient was "awake and very alert." Facial pruritus was initially reported by the patient more than four hours after the epidural morphine and naloxone $0.2 \mathrm{mg}$ was given intramuscularly two hours later "for excessive itching." One hour later (over seven hours after the epidural morphine) the itching was reported to be relieved by the naloxone but although the patient remained pain-free she was diaphoretic and had vomited some bile-coloured fluid. The nausea and vomiting continued despite the administration of intramuscular prochlorperazine $5 \mathrm{mg}$. More than nine hours after the epidural morphine the nursing staff notified the author because the patient was "extremely diaphoretic and felt faint" whenever she lifted her head. Vital signs remained normal, $\mathrm{CBC}$ and electrolytes done at this time were $\mathrm{Hgb}$ $119 \mathrm{~g} \cdot \mathrm{L}^{-1}$, Het $359, \mathrm{Na}+136 \mathrm{mmol} \cdot \mathrm{L}^{-1}, \mathrm{~K}+3.7$ $\mathrm{mmol} \cdot \mathrm{L} \cdot{ }^{-1}$

The patient was examined approximately eleven hours after the epidural morphine. She was extremely distressed, diaphoretic and clammy to the touch. The slightest movement of her head brought on paroxysms of nausea, with the sensation of "the world whirling around" her. Assessment of orthostatic hypotension was impossible because the patient could not tolerate the required movement of her head. But, her supine heart rate was 70 bpm and blood pressure was $120 / 60$. Although nystagmus on lateral gaze was not present the clinical picture was very similar to acute labyrnthitis. It was postulated because of the time of onset of symptoms that the epidural morphine might have been responsible for an acute and transient disruption of the vestibular apparatus.

As the patient had already received one dose of naloxone it was elected not to attempt reversal of her symptoms for fear of also reversing the postoperative analgesia, which had been excellent. She was monitored overnight with a pulse oximeter.

Seventeen and a half hours after the epidural morphine the patient felt "well" and within 22 hours was entirely asymptomatic, with no further dizziness or nausea. She was discharged home on the fourth postoperative day entirely well.

\section{Discussion}

There can be no proven relationship between this patient's acute symptomatology and the epidural morphine she received. Indeed, it may well have been a transient attack of viral labyrinthitis which coincided with her surgery. However, acute labyrinthitis classically lasts for two to three days, not hours. The onset of her symptoms, approximately seven hours after injection, is similar to the known timing of rostral spread of morphine from the lumbar epidural space to the intra-cerebral cerebro-spinal fluid. ${ }^{3}$ Trigeminal analgesia, nausea and vomiting, and peak respiratory depression generally occur from $6-10 \mathrm{hr}$ post-injection. The spontaneous resolution of symptoms within $17 \mathrm{hr}$ is also consistent with the expected duration of the central effect of epidurally injected morphine in regard to analgesia and other complications, such as respiratory depression, both of which can last up to $24 \mathrm{hr}$. '

Consideration was given to other possible causes of vertigo, such as a toxic effect of another agent. However, the morphine given was the preparation marketed for epidural use, without preservative. The effect of epidurally administered fentanyl would have been faster in onset and shorter in duration. The other medications given have been in common use in obstetrics and obstetrical anaesthesia for many years, with the possible exception of naloxone and prochlorperazine. However, naloxone was administered over one hour before the onset of nausea, vomiting and diaphoresis, although the time of onset of action should have been only $2-3$ min after intramuscular injection, ${ }^{4}$ while prochlorperazine was given 45 min after the onset of the signs and symptoms.

Lastly, consideration was given to the transient episode of intraoperative hypotension associated with the onset of sympathetic blockade. Although ischaemia has been postulated as a cause of labyrinthitis, this is generally in the chronic rather than the acute form of the disease. Furthermore, one would have expected an immediate onset of symptoms, temporally related to the hypotension, rather than a delay of nearly eight hours between cause and effect.

In conclusion, this case is presented because of its rarity and because of the concern it engendered while the patient was symptomatic, with no clear diagnosis and therefore no certainty as to prognosis. Should these symptoms present again in a similar patient greater reassurance could probably be given as to possible cause and expected duration of effect.

\section{Acknowledgement}

The author would like to thank Dr. Joanne Douglas for her helpful comments on the manuscript.

\section{References}

1 Cousins MJ, Mather LE. Intrathecal and epidural administration of opioids. Anesthesiology 1984; 61 : 276-310.

2 Leicht CH, Hughes SC, Dailey PA, Shnider SM, Rosen $M A$. Epidural morphine sulfate for analgesia after Cesarean section: a prospective report of 1000 patients. Anesthesiology 1986; 65: A366.

3 Bromage PR, Camporesi EM, Durant PAC, Nielsen $\mathrm{CH}$. Rostral spread of epidural morphine. Anesthesiology 1982; 56: 431-6.

4 Krogh CME (Ed.). Compendium of Pharmaceuticals and Specialties. Ottawa: Canadian Pharmaceutical Association, 1989, 652-3. 